\title{
The Use of Simulation in the Development of Human Factors Guidelines for Alarm Systems
}

\author{
John O'Hara and William S. Brown \\ Department of Advanced Technology \\ Brookhaven National Laboratory \\ Upton, NY 11973
}

\author{
Bruce Hallbert and Gyrd Skraaning \\ Halden Reactor Project \\ Halden, Norway
}

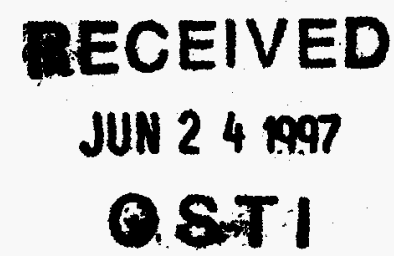

\begin{abstract}
This paper describes a research program sponsored by the U.S. Nuclear Regulatory Commission to address the human factors engineering (HFE) aspects of nuclear power plant alarm systems. The overall objective of the program is to develop HFE review guidance for advanced alarm systems. As part of this program, guidance was developed based on a broad review and analysis of technical and research literature. In the course of guidance development, aspects of alarm system design for which the technical basis was insufficient to support guidance development were identified. Experimental research is currently underway to address the highest priority topics: alarm processing and display characteristics. This paper provides an overview of our approach to guidance development and discusses the role of simulation in the development approach. Finally, the current simulator-based experiment is described to illustrate how the alarm system design features are being studied.
\end{abstract}

Keywords: human factors, man-machine system, human-system interface, alarm systems

\section{INTRODUCTION}

The need to improve the human factors engineering (HFE) of alarm systems has led to the development of advanced systems in which alarm data are processed beyond the traditional "one sensor - one alarm" framework. While this technology promises to be a means of correcting many known alarm system deficiencies, there is also the potential to negatively impact operator performance [1]. A research program, sponsored by the U.S. Nuclear Regulatory Commission (NRC), is underway to address the HFE aspects of nuclear power plant alarm systems. The objective of the study is to develop HFE review guidance for advanced, computer-based alarm systems. As part of the development effort, aspects of alarm design for which the technical basis was insufficient to support guidance development were identified and research to address the most significant issues was initiated.

The current status of the program is described in this paper. Section II is an overview of our approach to guidance development and discusses the role of simulation in the methodology. In Section III, the current experimental research is described to illustrate how the alarm system design features are being studied experimentally. The conclusions are presented on Section IV.

\section{DEVELOPMENT OF ALARM SYSTEM REVIEW GUIDANCE}

A. general methodology was established to develop HFE guidance to support the NRC's review of nuclear power plant (NPP) human-system interfaces (HSIs) [2]. The methodology has been applied to several areas of new HSI technology and the guidance has been integrated into NUREG-0700, Revision 1 [3]. The guidance development process is shown in Fig. 1. The process is designed to establish valid guidelines in a cost-effective manner. Validity is defined along two dimensions: "Internal" validity is the degree to which the individual guidelines are based upon an auditable research trail. "External" validity is the degree to which the guidelines are subjected to independent peer review. The peer review process is considered a good method of screening guidelines for conformance to accepted human engineering practices. Validity can be inherited from the source materials that are used to develop the guidelines. Thus, for example, for a specific topic there are sometimes existing documents, such as industry guidance documents and standards, that have an auditable research trail and have been the subject of extensive peer review. We refer to these as primary source documents. Where source materials lack validity, it must be established for the new guidance as part of the guidance development process itself.

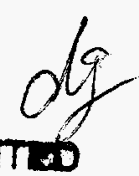


Primary source documents are sought first in our approach to guidance development since they already possess internal and extemal validity. Even when such documents are available, their guidance must still be adapted to an NPP HSI application. When primary source documents alone do not provide a sufficient basis on which to develop guidelines, additional sources of information are necessary. Secondary source documents are those with either internal or external validity (not both). Many industry guidance documents fit into this category. They are useful since their information is already expressed in guideline format. Either a good trail to their technical basis or a peer review should be established tás part of the design review guidance development. Tertiary documents, such as HFE handbooks, generally do not provide infemation in guidance form and they do not possess either form of validity. Thus, considerable effort may be involved in guideline preparation and validation when using these sources.

The three final sources of information for guidance development (see Fig. 1) require the most effort. Basic literature and industry experience are used where guidelines cannot be obtained from the other sources. Results are evaluated from basic literature including articles from refereed technical journals, reports from research organizations, and papers from technical conferences. Industry experience can be obtained from surveys and interviews. Industry experience is a valuable source of information for identifying performance issues associated with actual systems and for learning about proven design solutions.

Original research is the last category and refers to the systematic manipulation of the HSI design features of interest in order to determine their effects on performance under controlled conditions. The research should generally be performed in a dynamic, real-time context; e.g., a full-scope simulator or highfidelity engineering simulator. This type of research plays two important roles in guidance development: technical basis development and guidance confirmation. First, when the technical basis does not exist in the other source materials, the results of experiments can be used to fill the knowledge gap, i.e., to provide the information upon which design review guidance can be developed. For example, such studies can identify aspects of system design have a significant effect on human performance.

The second important role of experimental research is guidance confirmation. When guidance has been developed based on the other sources of information, as listed in Fig. 1, testing may be necessary to confirm that (1) the guidance is an acceptable extraction, synthesis, or interpretation of the data, and (2) that the guidance is appropriate to an NPP application.

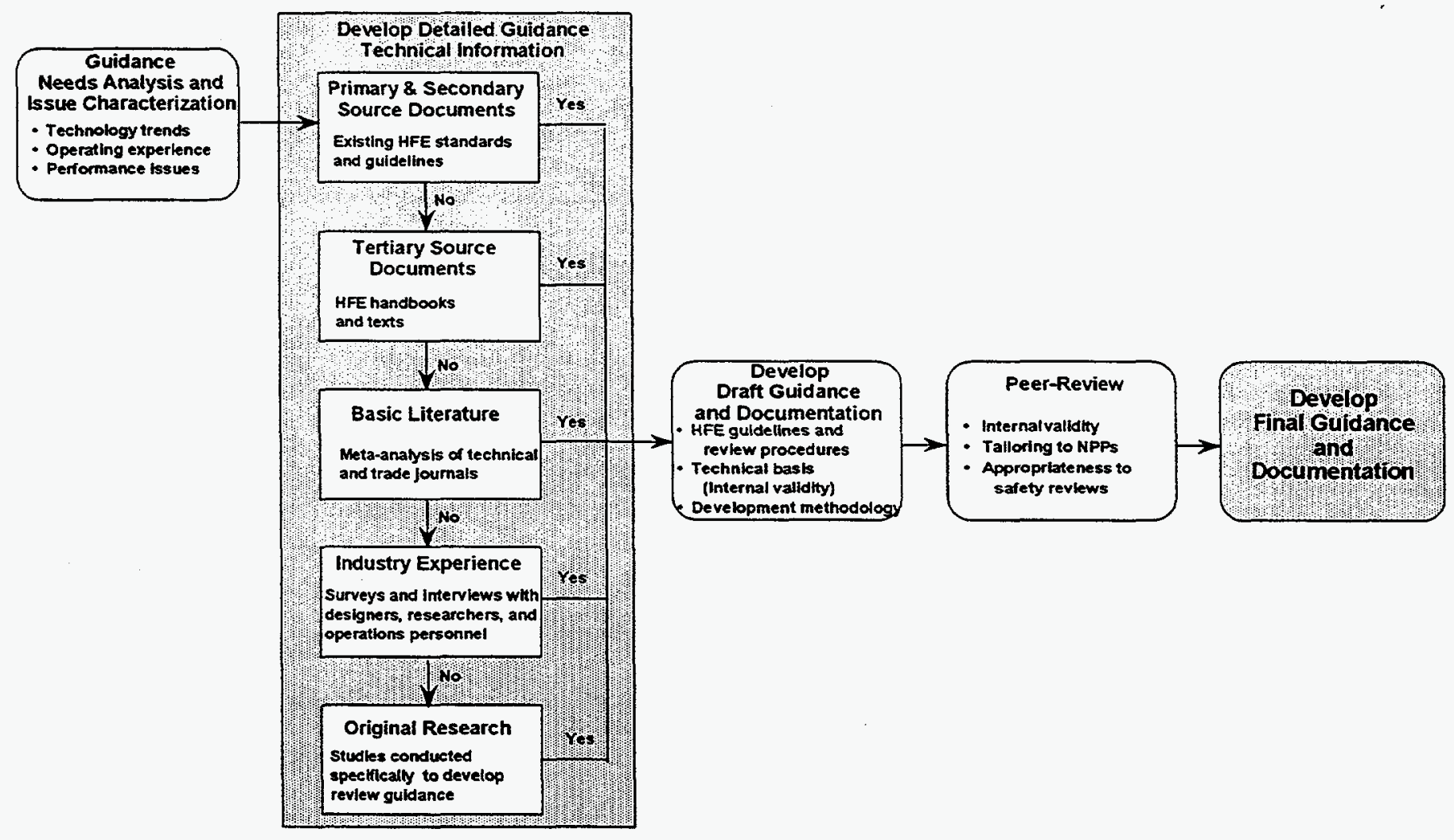

Fig. 1. Guidance Development Methodology 


\section{DISCLAIMER}

This report was prepared as an account of work sponsored by an agency of the United States Government. Neither the United States Government not any agency thereof, nor any of their employees, makes any warranty, express or implied, or assumes any legal liability or responsibility for the accuracy, completeness, or usefulness of any information, apparatus, product, or process disclosed, or represents that its use would not infringe privately owned rights. Reference herein to any specific commercial product, process, or service by trade name, trademark, manufacturer, or otherwise does not necessarily constitute or imply its endorsement, recommendation, or favoring by the United States Government or any agency thereof. The views and opinions of authors expressed herein do not necessarily state or reflect those of the United States Government or any agency thereof. 


\section{DISCLAMMER}

Portions of this document may be illegible in electronic image products. Images are produced from the best available original document. 
The great advantage of original research is the ability to focus on the specific design characteristics and human performance issues of interest. It has the disadvantage of being the most costly method of technical basis development relative to the range of issues that can be addressed. Further, such research can be limited in generalizability because any single experiment uses a relatively small sample of operators, a small sample of testbeds (plant types), and may be constrained by the specific way in which HSIs are designed for the study (see discussion in [5]).

Using this guidance development method, draft alarm review guidance was developed using each type of information source listed in Fig. 1 except for original research. Each individual guideline included the technical sources of information that formed its technical basis. This information serves as the basis for evaluating the internal validity of guidelines. The technical bases vary for each guideline. Some guidelines are based on technical conclusions from a preponderance of empirical evidence, some on a consensus of existing standards, and others on judgement that a guideline represents good practices. The draft guidelines were then evaluated by independent peer-reviewers who assessed: (1) the internal validity of the guidance, (2) the relevance of the guideline to the nuclear plant setting, and (3) the appropriateness of the guideline for NRC safety reviews. This peer review constitutes the external validation of the guidelines. A revision to the draft guidance based on the reviews was accomplished. The guidance development and technical basis are documented in NUREG/CR6105 [4] and the guidance itself is integrated into NUREG-0700 [3].

However, there were aspects of advanced alarm system design for which the available information did not fully support guidance development. A program of original research was developed to address these characteristics. This program is discussed in the next section.

\section{CURRENT RESEARCH}

During guidance development, several human performance issues associated with advanced alarm systems were identified. Those issues associated with alarm processing, availability, and display were considered to have the highest priority. These issues are summarized in Section A below (see [1] for the detailed literature review), the experimental methodology is presented in Section $B$, and the plan for data analysis is presented in Section $\mathrm{C}$.

\section{A. Processing, Availability, and Display Issues}

Alarm Processing: One of the most important objectives in the design of advanced alarm systems is to reduce the number of alarms that occur during plant disturbances. Alarm processing is intended to accomplish this objective. These techniques were developed to identify which alarms are significant and to reduce the crew's need to infer plant conditions. Alarm processing refers to the rules or algorithms that are used to determine the operational importance of alarm conditions. Many of the techniques can be classified into two categories based upon how the information that opcrators receive is affected. Nuisance Alarm Processing techniques essentially climinate alarms that are irrelevant to the current mode of the plant, e.g., a low temperature alarm on a line that is out of service for maintenance. Redundant Alarm Processing techniques analyze alarms to determine which are less important because they provide information that is redundant with other alarms. For example, in causal relationship processing only causes are alarmed and consequences are considered redundant. In addition to reducing the actual number of alarms, however, these redundant alarm processing techniques may adversely affect the information used by the operator for situation assessment, decision-making, or confirmation that the situation represented by the "true" alarm has occurred.

The various processing methods and the degree of alarm reduction should be evaluated for their relative effects on operator performance. However, research that has addressed the effects of alarm processing on performance has been equivocal. Some studies have found an effect of alarm processing on performance while others have not. This could be due to many factors such as type of processing used, degree of alarm reduction achieved, and user familiarization with the system. The effects could also be transient dependent, e.g., dependent on the specific scenario, on the operator's ability to recognize familiar patterns, or on plant type. System complexity should also be considered. The operator, as the system supervisor, should easily comprehend alarm information, how it was processed, and the bounds and limitations of the system. An alarm system combining multiple processing methods may be so complex that it cannot be readily interpreted by operators in time-critical situations. An understanding of this relationship is essential to the development of alarm system improvements and review guidance.

Alarm Availabilitv: This refers to the method by which the results of alarm processing are made available to the operating crew (rather than how they are presented, which is alarm display). Two of the techniques that have been used include suppression and dynamic prioritization. Suppression is when less important are suppressed and not presented to the operators, but can be accessed by operator request or by the alarm system based upon changing plant conditions. Dynamic prioritization is when less important alarms are presented to operators but somehow distinguished from those that are more important, such as presenting them in a different color or in a different location than other alarms.

Suppression also removes potentially distracting alarms; however, since they are accessible on auxiliary displays, additional workload may be imposed by requiring operator action to retrieve them. Dynamic prioritization does not conceal any information from operators. However, the operator must perceptually "filter" alarms (e.g., scan for red alarms) and a potential, therefore, exists for distraction from less important alarms. Thus, there are tradeoffs between these approaches and an issue remains concerning when the various options should be employed.

Alarm Display: Alarm displays can be considered along three dimensions: spatial dedication (whether an alarm is always 
displayed in the same physical location or in variable locations), display permanence (whether an alarmed is always visible or visible only when in an alarmed state), and integration (whether that alarms are presented as a separate system or integrated with other process information. These three dimensions distinguish three main types of alarm displays. Spatially-dedicated continuously-visible (SDCV) alarm displays provide a display of information in a permanent location. Lighted tile alarms are an example. Temporary alarm displays, such as a VDU message list, display alarm messages only when the alarm is in a valid state. Specific alarms usually not appear in spatially dedicated location although they may always be presented on the same VDU. Integrated alarms present alarm information as an integral part of other displays, such as process displays. For example, if alarms are built into a system mimic display, trouble with a component such as a pump can be depicted by a change in color or flashing of the pump icon. These displays may be in a fixed or variable location and are typically not permanent displays. While alarms have traditionally been separate information systems from other indicators, it is thought that the operator's information processing is supported by integration of information into a single displays. The benefits of these types of displays are thought to include: (1) enhancement of parallel processing (lowering cognitive workload), (2) enhancement of the operator's ability to better understand the relationships between display elements, and (3) enhancement of the operator's ability to develop a more rapid and accurate awareness of the situation.

SDCV displays are often preferred by operators and have been shown to have performance advantages under high-alarm conditions. But, placing all alarms on such displays (potentially many thousands of alarms in advanced plants) leads to the alarm overload problem for operators. VDU message lists have not been completely successful alternatives, however. Message lists have been demonstrated to be problematic in high-alarm conditions. Further, although the research is limited, integrated graphic displays have not been shown to improve performance. To serve the different functions of the alarm system, multiple display formats may be required. Thus the display format and the degree to which alarm information is integrated with other process information are important safety considerations. The role, relative benefits, and design of each type of alarm display format in the presentation of alarm information is an issue.

\section{B. Experimental Methodology}

To address the above issues, an experiment was performed to evaluate the impact of alarm processing, availability, and display characteristics on both plant and operator performance. The extent to which the number of alarms is reduced is a function of the alarm processing techniques that are applied. In this study, a variety of alarm processing methods were employed that are representative of near-term applications, and therefore, the possibility of near-term regulatory review. Three levels of alarm reduction were used. The first processed nuisance alarms to achieve moderate alarm reduction (called Tier I processing). The second processed redundant alarms, which in combination with nuisance alarm processing, achieved maximum reduction (called
Tier 2 processing). A third condition of no alarm processing was used to provide a baseline for comparison (called Tier 0 processing).

The differential effect of two types of alarm availability was evaluated: suppression and dynamic prioritization. For alarm suppression, less important alarms were not presented in the primary alarm displays but were available to operators on a suppressed alarm list. For dynamic prioritization, less important alarms were color coded to indicate their status.

Three types of VDU-based primary alarm displays were compared: a dedicated "tile-like" format, a mixed tile and message list format, and a mixed integrated graphic and message list format. The graphic integrates alarm information into process display formats. These display formats enabled the examination of two aspects of alarm display design: spatial dedication and degree of integration with process information. A secondary alarm display consisting of a chronological event list was also available to operators in each condition.

The various types of alarm processing, availability, and display were combined to form eight experimental conditions, i.e., unique alarm system configurations (see Table 1). In addition to varying alarm characteristics, two types of scenarios were used: complex and simple. Each of the eight configurations was tested in both a simple and a complex scenario.

The tests were conducted using the Human-Machine Laboratory (HAMMLAB) at the Halden Reactor Project in Norway. The plant model simulates a pressurized water reactor power plant with two parallel feedwater trains, turbines and

Table 1

Experimental Conditions

\begin{tabular}{llllll} 
Processing & P1 & \multicolumn{2}{c}{ P2 } & \multicolumn{2}{c}{ P3 } \\
Availability & NA & A1 & A2 & A1 & A2 \\
\hline
\end{tabular}

Display Type

D1 117

$\begin{array}{lllllll}\mathrm{D} 2 & 2 & 3 & 4 & 5 & 6\end{array}$

D3 8

Notes:
$\mathrm{D}=$ Display Type
D1: tile format;
D2: tile+message list
D3: integrated +message list
$\mathrm{P}=$ Processing
Pl: none
P2: Tier 1-nuisance
P3: Tier 2-redundant
$A=$ Availability
Al: prioritization
A2: suppression 
generators. It is closely related to the plant model used in the large scale training simulator at the Loviisa nuclear power station in Finland. The participants were professional nuclear power plant operators from the Loviisa plant. Six crews of operators participated each made up of a reactor operator and turbine operator. Each crew made 16 experimental trials, two in each of the eight alarm conditions (one with a scenario rated as low complexity and one in a scenario rated as high complexity). There were a total of 16 scenarios so that noscenario was used more than once for each crew. The order of presentation of scenarios was balanced, as was the relationship between individual scenarios and experimental conditions.

The measurement of performance in the study included process measures, operator task performance, and operator cognitive processes (e.g., situation awareness and workload). The subjective opinions of the operators were also obtained.

\section{Data Analysis Plan}

The experimental trials were recently completed and the data are currently being analyzed. The primary objectives of the analyses, and the experimental condition comparisons related to them, are:

1. To determine the effect of spatial dedication on performance; controlling for processing and availability: Experimental Condition 1 vs. 2 and Experimental Condition 7 vs. 4 vs. 8 .

2. To determine the effect of alarm integration on performance: Experimental Conditions 8 vs. [4\&7].

3. To determine the effect of alarm reduction and processing type (tier) on performance; with scenario effects included, collapsing across availability, and holding display constant: Experimental Conditions 2 vs. [3\&4] vs. [5\&6] and Experimental Conditions 1 vs. 7.

4. To determine the effect of alarm availability, alarm processing, and the interaction of availability and processing on performance; holding display constant: Experimental Condition 3 vs. 4 vs. 5 vs. 6 .

5. To determine the effect of the interaction of display type and processing; with scenario effects included: Experimental Conditions 1 vs. 2 vs. 7 vs. 4 .

6. To determine the effect of scenario complexity and its interactions with other variables on performance (analyzed in each comparison listed above).

These effects are primarily being tested with repeated measures analyses of variance.

\section{CONCLUSIONS}

The nuclear and human factors communities have developed a significant database upon which HFE review guidance for advanced alarm systems was developed. Information supporting guidance development was available not only from alarm guidance documents, but also from published reports of research and operational experience. Further, advanced alarm systems, particularly those utilizing computer-based interfaces, share many HSI characteristics with other control room resources. Thus HFE principles associated with VDUs, graphics displays, dialog structures (such as menus and command language) and computer input devices (such as touch screens, keyboards, and trackballs) are applicable to alarm systems. This information was used to develop HFE guidance for the review of alarm systems.

It was also found that notable human performance issues remain unresolved, related to alarm processing, availability, and display. Focused research is being used to better understand these issues and contribute to the development of guidance in these areas. The data are currently being analyzed and will be reported on shortly.

\section{ACKNOWLEDGEMENTS}

This research is being sponsored by the U.S. Nuclear Regulatory Commission. The views presented in this paper represent those of the authors alone, and not necessarily those of the NRC. The authors wish to extend our gratitude to our colleagues at the NRC, BNL, and Halden who contributed to this project and to the Imatran Voima Oy - Loviisa NPP personnel who shared their knowledge and expertise with the project staff.

\section{REFERENCES}

[1] J. O'Hara and W. Brown. Advanced Alarm Systems and Human Performance," BNL Report A3967-1-6196, U.S. Nuclear Regulatory Commission, Washington, D.C. (1996).

[2] O'Hara, J. (1994). Advanced Human System Interface Design Review Guideline (NUREG/CR-5908), Volume 1: General evaluation model, technical development, and guideline description. Washington, D.C.: U.S. Nuclear Regulatory Commission.

[3] NRC, "Human-System Interface Design Review Guideline," NUREG-0700, Rev. 1, Washington, D.C.: U.S. Nuclear Regulatory Commission (1996).

[4] J. O'Hara, W. Brown, J. Higgins, and W. Stubler, "Human Factors Engineering Guidelines for the Review of Advanced Alarm Systems," NUREG/CR-6105, U.S. Nuclear Regulatory Commission, Washington, D.C. (1994).

[5] O'Hara, J., Stubler, W., \& Brown, W. \& Higgins, J. (1997). Integrated system validation: Methodology and review criteria (NUREG/CR-6393). Washington, D.C.: U.S. Nuclear Regulatory Commission. 


\section{DISCLAIMER}

This report was prepared as an account of work sponsored by an agency of the United States Government. Neither the United States Government nor any agency thereof, nor any of their employees, makes any warranty, express or implied, or assumes any legal liability or responsibility for the accuracy, completeness, or usefulness of any information, apparatus, product, or process disclosed, or represents that its use would not infringe privately owned rights. Reference herein to any specific commercial product, process, or service by trade name, trademark. manufacturer, or otherwise does not necessarily constitute or imply its endorsement, recommendation, or favoring by the United States Government or any agency thereof. The views and opinions of authors expressed herein do not necessarily state or reflect those of the United States Government or any agency thereof. 